\title{
Synthetic biology: From the first synthetic cell to see its current situation and future development
}

\author{
ZHANG LiuYan, CHANG SuHua \& WANG Jing* \\ Key Laboratory of Mental Health, Institute of Psychology, Chinese Academy of Sciences, Beijing 100101, China
}

Received July 29, 2010; accepted October 19, 2010

\begin{abstract}
Synthetic biology is an emerging field, which, since its birth, has shown great value and potential in many fields including medicine, energy, environment and agriculture. It is also important for the study of the origin and evolution of life. Since the publication of the first synthetic cell in May, 2010, synthetic biology again attracts high attention and leads to extensive discussions all over the world. There have been a number of researches and achievements on synthetic biology in the United States and European countries. While in China, so far there is no systematic research on synthetic biology. In order to promote the development of this new discipline in China, we organized this review to systematically introduce the concept and research content of synthetic biology, summarize the achievements, and investigate the current situation in both China and abroad. We also analyzed the opportunities and challenges in synthetic biology, and looked forward to the future development of synthetic biology, especially its future development in China.
\end{abstract}

synthetic cell, synthetic biology, minimal genome

Citation: Zhang L Y, Chang S H, Wang J. Synthetic biology: From the first synthetic cell to see its current situation and future development. Chinese Sci Bull, 2011, 56: 229-237, doi: 10.1007/s11434-010-4304-z

On May 21, 2010, researchers in J. Craig Venter Institute (JCVI) published on Science their latest achievement on the creation of the first synthetic cell, as labeled JCVI-syn1.0, which was controlled by a completely chemically synthesized genome [1]. This achievement upon its publication has brought great concerns and extensive discussions in both scientific community and social society. The birth of the first synthetic cell indicates an important breakthrough in synthetic biology, which is an emerging field showing great value and potential in many fields, including medicine, energy, environment and agriculture. According to the report by The Royal Academy of Engineering of United Kingdom in 2009, it is expected that synthetic biology will create new significant industries, and the development of this field will have great impact on the future economy of United Kingdom, Europe and even all over the world [2]. Researchers from a wide range of disciplines, including

*Corresponding author (email: wangjing@psych.ac.cn) biology, computer science, engineering and mathematics, have been attracted to devote themselves to the research of synthetic biology. Numerous projects on synthetic biology have been proposed. A flourish of synthetic biology has been envisioned especially in Europe and USA. In order to promote the development of synthetic biology in China, here in this article, we made a systematic review on synthetic biology, including its basic concept, research content, and key achievements. We also investigated its current situation in both China and abroad. At last, we analyzed the opportunities and challenges in synthetic biology, and looked forward to the future development of synthetic biology, especially its future development in China.

\section{An overview of synthetic biology}

\subsection{Concept}

The definition of synthetic biology keeps evolving with a 
decade of development. So far there is no official or formal definition. According to the definition from the Synthetic Biology Community (http://syntheticbiology.org/), which is the most widely accepted concept, synthetic biology is the design and construction of new biological parts, devices and systems and the re-design of existing natural biological systems for useful purposes. Synthetic biology on the one hand is important to explore the origin and evolution of life, on the other hand, it has a broad range of applications ranging from health care (diagnostics and therapeutics), environment (biosensors, bioremediation), energy (biofuel) to agriculture (optimized food), through engineering the biological systems or modules [2-5]. One of the key features of synthetic biology is to apply the engineering principles to biological studies. The pipeline for engineering design, described as specification, design, modeling, implementation and testing/validation, was introduced into the design and construction of biological systems (Figure 1). Under the principle of synthetic biology, the complex life system can be treated as an organic combination of various functional elements. Synthetic biology starts from specification and standardization of biological parts, and then assembles the parts into devices and systems step by step [6]. The standardization of biological parts helps to improve the controllability and predictability of designed modules. Figure 2 shows the feature of synthetic biology and its difference in comparison to traditional genetic engineering.

The origin and development of synthetic biology are based on the development of current science and technologies including biotechnology, computer science, chemistry and so on. Meanwhile, the development of synthetic biology also fosters the birth of new science and technology. Knowledge from genomics, genetics, molecular biology, cell biology and systems biology facilitates our understanding on life system; skills from bioinformatics, computer science

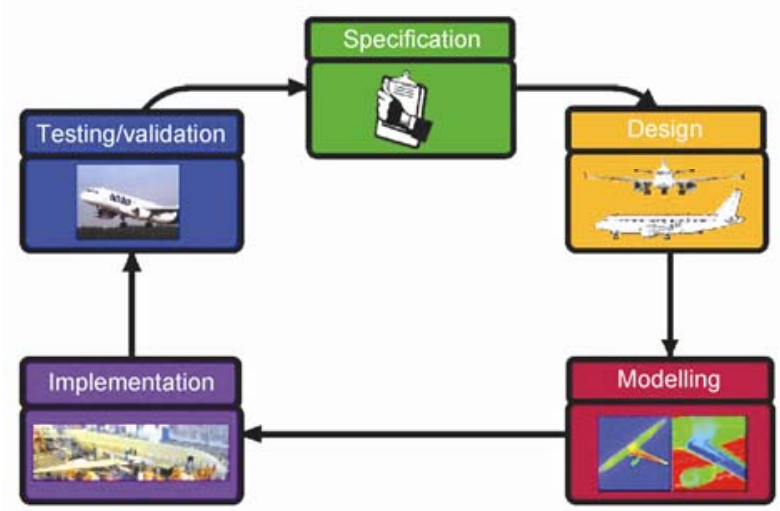

Figure 1 Engineering Cycle. The Engineering Cycle starts with defining the specification for the device or system which is to be designed and built. The next step in the process is to design the device or system on the basis of the specification. Frequently in engineering the design is then tested by extensive modeling. In the case of synthetic biology this is almost always an important step. Modeling is followed by implementation, testing and validation [6].
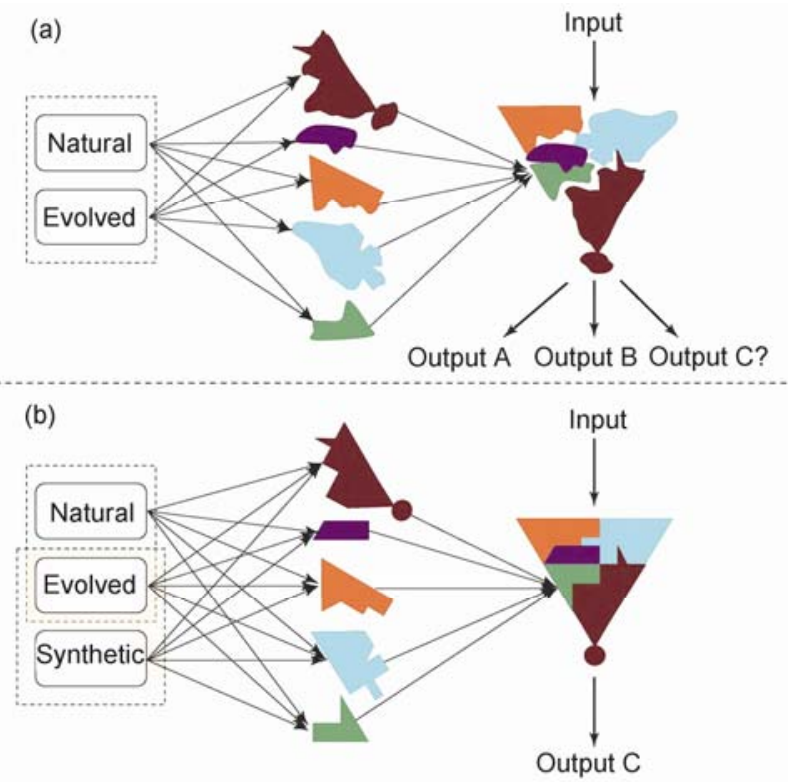

Figure 2 A representation of the design process of traditional genetic engineering (a) and synthetic biology (b). Both traditional genetic engineering and synthetic biology employ naturally occurring and modified biological components to construct an engineered system. However, because the building blocks and assembly methods of traditional genetic engineering methods are not well characterized, they often result in unanticipated interactions that can lead to suboptimal integration and pleiotropic effects when assembled into a larger system. This means that the output is frequently unpredictable and strongly dependent upon both the selection of specific parts and the methods for assembly. By contrast, synthetic biology begins with developing standardized biological components, with standardized interfaces that are fixed to promote optimal integration. The result should be highly predictable engineered systems with a single output for a single input [5].

and mathematics provide technical support on life design; while accumulated experiences on genetic and metabolic engineering etc. enable the process of life engineering. Synthetic biology can not only optimize life, but also can create new life. In this respect, we may regard synthetic biology as a revolutionarily new biotechnology.

\subsection{Main research contents}

Synthetic biology aims to synthesize new life form or engineer the existing life for useful purposes. Current researches are mainly focused on 3 aspects: (1) standardization of bio-parts and the design and construction of biological modules; (2) minimal genome; and (3) synthetic genomics.

(i) Standardization of bio-parts and the design and construction of biological modules. A bio-part, or BioBrick, usually refers to a short segment of DNA which acts as a promoter, terminator, protein coding sequence, or any other functional element. Standardization of bio-parts is a process to characterize and specify the bio-parts, including a detailed description and quality control testing by following certain standards. The highly characterized bio-parts make the design and construction of biological modules (devices, 
systems) much easier. The interaction of various elements in biological system is similar to that in electronic system. Based on these similarities, genetic circuits were designed and constructed (Figure 3). The design and construction of biological modules not only include the de novo design and construction of new biological modules, but also the re-design of the existing natural biological systems.

(ii) Minimal genome. Newly designed/re-designed bio-modules need to be loaded into a proper vector (chassis) to express and function. An ideal chassis is supposed to have a simplified but robust genome, i.e. "minimal genome", to reduce background noise and complexity, and to improve predictability and controllability of the new system. A minimal genome is a collection of essential gene contents which has the ability to sustain normal cellular life under ideal conditions, that is, in the presence of a full complement of essential nutrients and in the absence of environmental stress [8]. So the key question for minimal genome research is to identify the essentiality of genes. Usually there are two strategies [9] to get a minimal genome: the top-down strategy which aims to delete the non-essential segments from existing natural genomes, and the bottom-up strategy which obtains a minimal genome by de novo synthesis and assembly of essential genes. It should be noted that here the "minimal genome" is not an absolute concept but a relative concept in comparison to natural genomes. Usually the living condition and research objective help define the boundary of a minimal genome [10]. It is hard to get a universal chassis suitable for different research or application purposes. With more microbial genomes being sequenced, the rich database of genome sequences, as well as the rapid development of DNA sequencing and synthesis techniques, provide strong foundations for the construction of minimal genomes.

(iii) Synthetic genomics. This includes the design, chemical synthesis and assembly of whole genome. Sequencing technology endows us to read the genome to understand life forms, computational modeling and simulation facilitate the in silico design, while DNA synthesis technology enables us to write the genome for new life forms. So a systematic technical system on synthetic genomics is an important premise for the development of synthetic biology.

\section{Current research situation of synthetic biology}

Since year 2000, driven by Drew Andy, Jay D. Keasling, James J. Collins et al., progresses have been made in bio-parts standardization and genetic circuit design. The establishment of The BioBricks Foundation (http://openwetware. org/ wiki/The_BioBricks_Foundation) and Registry of Standard Biological Parts (http://partsregistry.org/ Main_Page) further promote the development of this area. The minimal genome and synthetic genomics research in JCVI also made big achievements. The recent publication on the first synthetic cell represents a milestone in synthetic biology. Meanwhile, there are more than ten genome reduction projects have been finished and the corresponding techniques have been developed and are getting mature.

\subsection{Standardization of bio-parts and the design and construction of biological modules}

In year 2000, the successful synthesis of genetic toggle switch [11] and genetic repressilator [12] represent the beginning of synthetic biology [13]. In 2003, the Synthetic Biology Community and the Registry of Standard Biological Parts were founded in Massachusetts Institute of Technology (MIT). In 2004, the first International Genetically

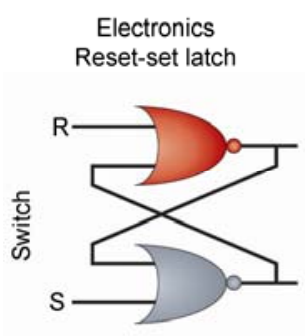

LC oscillator circuit

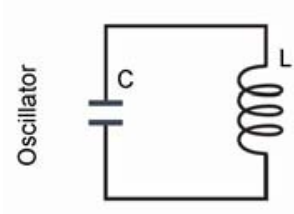

Biology

Bacteriophage $\lambda$ lysis-lysogeny switch

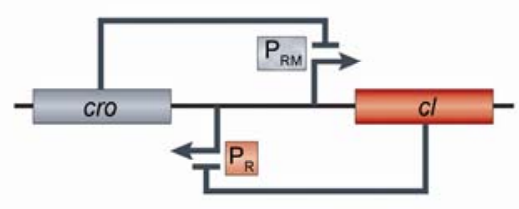

Cyanbacteric circadian oscillator

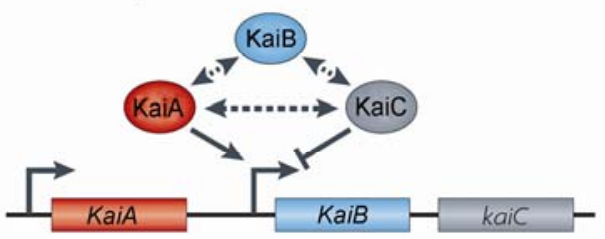

Synthetic biology

Genetic toggle switch

$$
\text { Heat }
$$

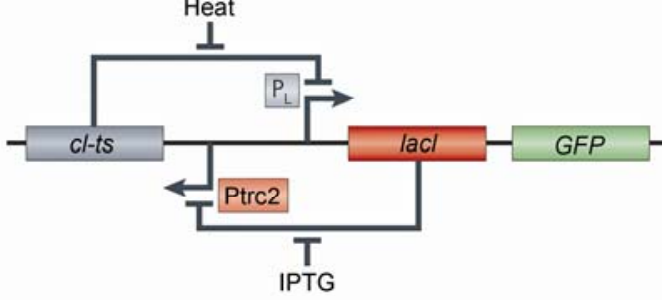

Repressilator

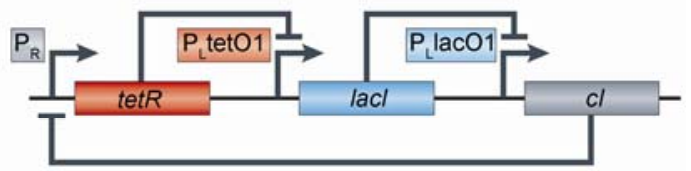

Figure 3 From electronic systems to engineered synthetic biology systems. Switches and oscillators that occur in electronic systems are also seen in biology and have been engineered into synthetic biological systems [7]. 
Engineered Machine Competition (iGEM) was held in MIT. The BioBricks Foundation (BBF) was established and the first International Meeting on Synthetic Biology was held in the same year. iGEM is a worldwide Synthetic Biology competition aimed at undergraduate students. Till 2010, there have been more than 120 teams from different countries participating it including about 2000 participants. Universities from China have participated this competition since 2007 and have made outstanding achievements. Major events [14] on bio-parts standardization and genetic circuit design are listed in Table 1.

There are several successful researches on genetic circuit design. It is worth to mention that the research team led by Jay D. Keasling [17,22] successfully engineered bacterium to produce the chemical precursor of artemisinin - the best drug available today to cure malaria. Multiple genes from bacterium, yeast and plant were involved and designed to make an engineered organism which has the ability of producing artemisinic acid with high efficiency. Once this achievement was applied to industrial production, the cost of anti-malaria drug would be greatly reduced. This event also indicates the great value and prospect of synthetic biology in medicine field.

Researches aiming for biofuel production using synthetic biology techniques were also proposed. In 2007, Zhang et al. [28] published their results of high-yield hydrogen production from starch and water by a synthetic enzymatic pathway under mild reaction conditions. In 2010, Keasling and his colleagues [29] implemented the microbial production of fatty-acid-derived fuels and chemicals from plant biomass using synthetic biology techniques. Both of these achievements indicate the great potential of synthetic biology on green energy production.

\subsection{The minimal genome research}

The minimal genome research began in year 1995 with the publication of the genome sequence of Mycoplasma genitalium, which is regarded to have the smallest genome among free-living organisms [30]. The genome size of $M$. genitalium is $580 \mathrm{~kb}$ coding about 480 genes. This inspired scientists to seek for a minimal genome which can sustain a normal cellular life. In addition, minimal genome study provides an important perspective to explore the mystery of the origin and evolution of life.

One of the key points of minimal genome research is to define the essentiality of genes for a cell. Comparative genomics [31,32], large-scale gene inactivation experiments [33-38], and network-based prediction [39] have been used to identify essential genes. Studies related to essential genes have been reviewed in refs [10,40]. After experimental identification, results show that even in the genome of $M$. genitalium, there are about 100 protein coding genes regarded as non-essential [34]. Researches on E. coli or B. subtilis show that no more than ten percents of genome content are essential for both of them [36,41].

Some genome reduction projects have been finished by using different strategies. The most common methods are suicide plasmid-mediated genomic deletion, linear DNAmediated genomic deletion, site-specific recombinationmediated genomic deletion, and transposon-mediated random deletion. The detail description of these methods can be found in refs [40,42]. Summary of the finished genome reduction projects are listed in Table 2.

\subsection{The design, synthesis and assembly of whole genome}

(i) Synthesis of viral genome. During 1970s, the establishment and development of DNA synthesis and recombinant DNA technologies had greatly promoted the research of genetic engineering and related biological studies. In 1970, Agarwal et al. [55] at the first time chemically synthesized the gene for an alanine transfer ribonucleic acid

Table 1 Major events on bio-parts standardization and genetic circuit design

\begin{tabular}{|c|c|}
\hline Year & Event \\
\hline 2000 & The first genetic toggle switch and repressilator were constructed by Gardner et al. [11] and Elowitz et al. [12], respectively. \\
\hline 2002 & The directed evolution of genetic circuits [15] and the stochastic gene expression in a single cell [16] were achieved. \\
\hline 2003 & $\begin{array}{l}\text { Students from MIT and Cambridge University designed biological oscillators based on the Elowitz repressilator. } \\
\text { A mevalonate pathway was engineered in Escherichia coli for the production of terpenoids which is a precursor to artemisinin [17]. } \\
\text { The Synthetic Biology community and the Registry of Standard Biological Parts were established. }\end{array}$ \\
\hline 2004 & $\begin{array}{l}\text { The first iGEM was held in MIT. } \\
\text { The First International Meeting on Synthetic Biology was held in MIT. } \\
\text { Programmed bacterial population control [18] and a mammalian toggle switch [19] were achieved. }\end{array}$ \\
\hline 2005 & Programmed pattern formation [20] and the artificial cell-cell communication in yeast [21] were achieved. \\
\hline 2006 & Production of the anti-malarial drug precursor artemisinic acid in engineered yeast [22] was achieved. \\
\hline 2007 & $\begin{array}{l}\text { RNAi and the repressor protein switch [23], RNAi-based logic circuits [24] and ribosome switches were achieved [25]. } \\
\text { For the first time, Chinese students participated in the iGEM competition. Team from Peking University won the Grand Prize [26], and team from } \\
\text { University of Science and Technology of China won the award of "Best Foundational Tech." }\end{array}$ \\
\hline
\end{tabular}


Table 2 Summary of genome reduction projects [42]

\begin{tabular}{|c|c|c|}
\hline Strain & Deletion size & Deleted functions(D) and new characteristics(C) \\
\hline \multicolumn{3}{|l|}{ Escherichia coli } \\
\hline$\Delta 20-4$ & $218.7 \mathrm{~kb}(5.6 \%)[43]$ & (D) Random genomic regions \\
\hline \multirow[t]{2}{*}{$\mathrm{CD} \Delta 3456$} & $313.1 \mathrm{~kb}(6.7 \%)[44]$ & (D) Nonspecific target regions \\
\hline & & (C) Presentation of mutually exclusive regions \\
\hline \multirow[t]{2}{*}{ MDS12 } & $376.1 \mathrm{~kb}(8.1 \%)[45]$ & (D) K-strain-specific islands \\
\hline & & (C) No significant difference to the parent cell \\
\hline \multirow[t]{2}{*}{ MDS43 } & $708.3 \mathrm{~kb}(15.3 \%)$ [46] & (D) K-islands, mobile elements \\
\hline & & (C) Increased genome stability and electroporation efficiency \\
\hline \multirow[t]{2}{*}{ MGF-01 } & $1.03 \mathrm{Mb}(22 \%)[47]$ & (D) Nonessential regions without growth deficiency \\
\hline & & (C) Increased threonine production (2-fold) \\
\hline \multirow[t]{2}{*}{$\Delta 16$} & $1.38 \mathrm{Mb}(29.7 \%)[48]$ & (D) Nonessential genes in the literature \\
\hline & & (C) Growth deficiency, abnormal nucleoid location \\
\hline \multicolumn{3}{|l|}{ Bacillus subtilis } \\
\hline$\Delta 6$ & $320 \mathrm{~kb}(7.7 \%)[49]$ & (D) Prophage, polyketide synthesis \\
\hline \multirow[t]{2}{*}{ MG1M } & $991 \mathrm{~kb}(24 \%)[50]$ & (D) Prophage, polyketide synthesis, secondary metabolites \\
\hline & & (C) Growth deficiency \\
\hline MGB874 & $873.5 \mathrm{~kb}(20.7 \%)[51]$ & (C) Increased productivity of extracellular cellulose (1.7-fold) and protease ( 2.5 -fold) \\
\hline Corynebacterium glutamicum & $190 \mathrm{~kb}(5.7 \%)[52]$ & (D) R-strain-specific regions \\
\hline Schizosaccharomyces pombe & $\sim 500 \mathrm{~kb}(4 \%)[53]$ & (C) Growth at a lower rate \\
\hline Saccharomyces cerevisiae & $531.5 \mathrm{~kb}(5 \%)[54]$ & (C) Increased production of ethanol (1.8-fold) and glycerol (2-fold) \\
\hline
\end{tabular}

from yeast. The gene was composed of 77 nucleotides. After that, DNA synthesis technology developed fast, and a variety of active viral genomes were synthesized (Table 3).

(ii) Synthesis of bacterial genome. In comparison to viruses, bacteria usually have bigger genomes and higher complexity. Venter and his team in JCVI spent 15 years in creating the first synthetic cell with the ability of self-replication. In general, there are 3 major technical challenges [60]: (1) De novo chemical synthesis and self-assembly of a complete genome; (2) genome transplantation between cells, prokaryotic or eukaryotic, to make the transplanted genome control the receptor cell; and (3) transplantation of a synthesized genome to a cell and make the donor genome control the receptor cell. Some other challenges also need to be tackled, such as the test of SNPs, quality control of DNA synthesis, DNA methylation, etc. It is estimated that about 40 million U.S. dollars were spent with over a decade efforts from 20 people for creation of such a synthetic cell [61]. Historical events of the synthetic genomic study in JCVI are listed in Table 4.
The synthetic genome was designed based on the genome sequence of $M$. mycoides. To distinguish the synthetic genome from the natural one, 4 watermark sequences were designed to replace one or more cassettes in regions not interfering with cell viability [1]. The synthetic genome was produced with 1078 of 1080-bp cassettes which covered the whole designed genome. These cassettes were all chemically synthesized, and the ends of each cassette had 80-bp overlaps to adjacent cassettes to facilitate their assembly. A three-stage strategy was utilized to assemble the genome from these cassettes by transformation and homologous recombination in yeast. First, 109 of 10080-bp assemblies were stitched, then 11 of 100000-bp assemblies, and finally the complete genome with 1077947-bp length. The intact synthetic $M$. mycoides genomes from the yeast were transplanted into the restriction-minus $M$. capricolum recipient cells by using techniques described in ref. [66]. After culturing and selection, a blue colony of bacteria was found to rapidly grow on a lab plate, which was subsequently identified as the synthetic transplants.

Table 3 Summary of viral genome synthesis

\begin{tabular}{ccc}
\hline Time $^{\text {a) }}$ & Event & Genome size (kb) \\
\hline Aug. 2002 & Chemical synthesis of poliovirus cDNA without natural template [56] & 7.5 \\
Dec. 2003 & Generating a synthetic genome by whole genome assembly: $\Phi$ X174 bacteriophage from synthetic & oligonucleotides [57] \\
Oct. 2004 & Synthesis of the genome which present enhanced virulence of influenza: A viruses with the haemagglutinin & 5.4 \\
of the 1918 pandemic virus [58] 2008 & Synthesis of a recombinant bat SARS-like corona-virus [59] & $1.7(\mathrm{HA})+1.4(\mathrm{NA})$ \\
\hline
\end{tabular}

a) According to the publish date of the results. 
Table 4 Historical events of the synthetic genomic study in JCVI

\begin{tabular}{|c|c|}
\hline Time $^{a)}$ & Event \\
\hline Oct. 1995 & The whole genome sequencing of Mycoplasma genitalium was completed [30] \\
\hline Dec. 1999 & $\begin{array}{l}\text { After identified by global transposon mutagenesis, it is estimated that there are about 265-350 genes are essential in } \\
\text { the genome of } M \text {. genitalium [62] }\end{array}$ \\
\hline Dec. 2003 & Generating a synthetic genome by whole genome assembly in two weeks: $\Phi$ X174 bacteriophage from synthetic oligonucleotides [57] \\
\hline Jan. 2006 & Identified 382 essential genes among 482 coding sequences of $M$. genitalium by using single gene mutation [34] \\
\hline Aug. 2007 & Genome transplantation in bacteria: Changing one species to another [63] \\
\hline Jan. 2008 & Complete chemical synthesis, assembly, and cloning of a M. genitalium genome [64] \\
\hline Dec. 2008 & One-step assembly in yeast of 25 overlapping DNA fragments to form a complete synthetic M. genitalium genome [65] \\
\hline Sep. 2009 & Creating bacterial strains from genomes that have been cloned and engineered in yeast by using genome transplantation techniques [66] \\
\hline May 2010 & Creation of a bacterial cell controlled by a chemically synthesized genome [1] \\
\hline
\end{tabular}

The creation of the first synthetic cell is an important milestone in the development process of synthetic biology. Through this work, a technical system (or to say, a toolkit) including genome design, chemical synthesis and assembly, and genome transplantation were established, which can be utilized for further research and applications.

\section{Development status of synthetic biology}

\subsection{Synthetic biology in Europe and United States}

Synthetic biology, as a newly emerging field, has gained great attention since its birth. In 2004, synthetic biology was elected as one of the top ten new techniques by Technique Review in U.S. In 2007, a research report named "Genome Synthesis and Design Futures: Implications for the U.S. Economy" was published by Bio-era of U.S. In 2008, "Creating Life" was listed as one of the Top Ten Scientific Discoveries by Times. In May 2009, the Royal Academy of Engineering in U.K. released the report named "Synthetic Biology: scope, applications and implications", in which a systematic introduction, the application prospects and social impact of synthetic biology were illustrated. During the last decade, U.S. and European countries have invested a huge amount of money to support the development of synthetic biology.

After the Human Genome Project (HGP), the U.S. Department of Energy started the "Genome To Life" project, which included the synthetic genomics research. In 2006, the Synthetic Biology Engineering Research Center (SynBERC) was founded by funding from U.S. National Science Foundation. The partner institutions of SynBERC include UC Berkeley, UC San Francisco, Harvard, MIT, Stanford, and Prairie View A\&M University. In Europe, in 2005, European Commission published the project report named "Synthetic Biology: Applying Engineering to Biology" as a part of the 6th Framework Programme. Later in 2007, the European Commission started 18 leading projects on synthetic biology. In U.K., synthetic biology was listed as high-priority funded research field by Biotechnology and
Biological Sciences Research Council (BBSRC) in 2008. Investigation report released by The Woodrow Wilson International Center for Scholars on June 4th 2010 shows that since 2005, the U.S. government has spent approximately $\$ 430$ million on synthetic biology projects. For comparison, the European Commission and 3 European countries, namely the Netherlands, the United Kingdom and Germany, have spent approximately $\$ 160$ million on synthetic biology research (Figure 4). The funding keeps increasing in all these western countries.

\subsection{Synthetic biology in China}

Synthetic biology also attracts big attention and enthusiasm from scientists in China. The theme "Artificial Life" was listed in the 50-year scientific development roadmap by the Chinese Academy of Sciences (CAS). In February 2008, the Xiangshan Conference on synthetic biology was held by professor ZHANG ChunTing from Tianjin University, professor WEI JiangChun from Institute of Microbiology, CAS, and Professor SUN ZhiRong from Tsinghua University. This is the first academic conference about synthetic biology in China. In July 2009, the Key Laboratory of Synthetic

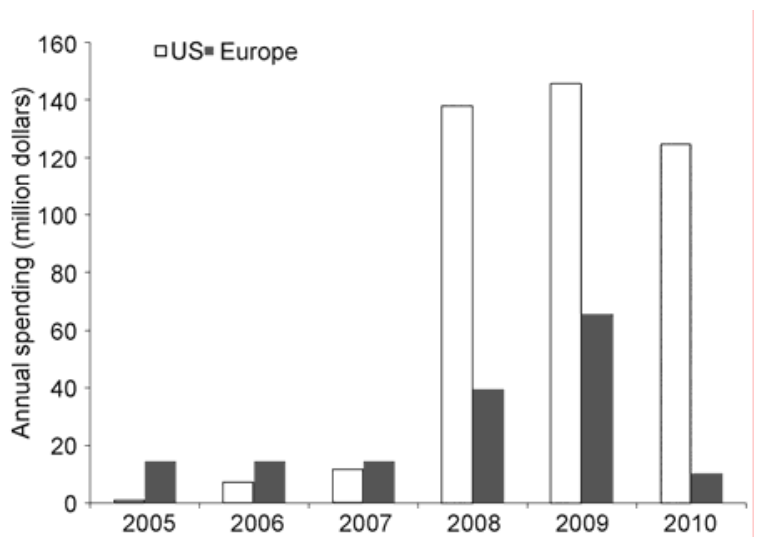

Figure 4 The annual spending of the U.S. government agencies, the European Commission and 3 individual European countries (from http:// www.synbioproject.org/library/publications/archive/researchfunding/). 
Biology of CAS organized a forum on the design of drug and energy products based on synthetic biology techniques. Beijing Institute of Life Science, CAS organized two forums on synthetic biology in Aug. and Nov. 2009, respectively. A group of academicians, experts and scholars were invited to discuss the current status and development strategies of synthetic biology aiming to promote its development in China. In Dec. 2009, the Eastern Technology Forum named "Basic and Frontier Issues of Synthetic Biology" was held and co-organized by Shanghai Jiao Tong University (SJTU) and Shanghai Institutes for Biological Sciences, CAS. In July 2010, supported by China Association for Science and Technology (CAST), the academic seminar on "Ethics and Bio-security Issues of Synthetic Biology" was held in Suzhou. Meanwhile, some research centers about synthetic biology were established, including the Systems and Synthetic Biology Research Center in Tianjin University, Key Laboratory of Synthetic Biology of CAS and the Synthetic Biology and Bioinformatics Center in the Academy of Military Medical Sciences.

Chinese researchers have received some achievements on synthetic biology as well. For example, the bioinformatics center of Tianjin University built the Database of Essential Genes (DEG) to collect the published experimental essential genes and provide alignment service [67,68]. Scientists from the Key Laboratory of System Bioengineering in Tianjin University designed, simulated and constructed an environment-sensitive synthetic microbial ecosystem which provides valuable information for addressing questions in ecology and may act as a chassis for construction of more complex microbial ecosystems [69]. Research team from Ministry of Education Key Laboratory of Bioinformatics in Tsinghua University realized the reverse engineering of bacterial chemotaxis pathway by employing control theory and frequency domain analysis [70]. The iGEM team in Peking University continued their awarded project and synthesized a novel genetic sequential logic circuit: A push-on push-off switch which has the ability to generate different outputs in response to the same input signal on the basis of its internal state, and "memorize" the output [26]. Researchers from University of Science and Technology of China (USTC) developed and demonstrated reusable and combinable designs for transcriptional logic gates which laid foundation for the reuse and combinational design in synthetic biology [71]. On the other hand, Chinese scientists also actively participated in international collaboration on synthetic biology research. For example, research team from Institute of Psychology, CAS participated in the synthetic biology project, the Programmable Bacterial Catalysts (PROBACTYS), of the 6th Framework Programme of European Union. As the only research team from non-European countries, they made great contribution on genome-scale metabolic network reconstruction and modelling.

College students in China have also engaged in the study and research of synthetic biology. Recent years, there have been many teams from Peking University, Tsinghua University, USTC, Tianjin University and SJTU participating the iGEM competition, and have made remarkable achiev- ements. Chinese scientists have made great achievements on synthetic insulin and synthetic tRNA, which can be regarded as the earlier foundation of synthetic biology. The development of science and technology in China has shown that China has the ability to make more achievements in synthetic biology.

\section{Opportunities and challenges of synthetic biology}

Synthetic biology has shown us its great potential and prospects in both basic and applied research, as well as its promising applications to improve human life, such as cheaper drug, faster disease diagnosis, efficient production of green energy, air cleaning and so on. However, there are still many challenges for the further development of synthetic biology.

\subsection{Technical challenges}

A publication on Nature listed 5 hard truths for synthetic biology: many of the parts are undefined; the circuitry is sometimes unpredictable; the complexity is still unwieldy; many parts are incompatible; variability may crash the system [72, 73]. The key point lies in our still limited understanding of cellular life. HGP brought the -omics idea into biology science. Different levels of -omics studies have generated plenty of data, which provide sound foundation for novel biological discoveries. Life is a complex networking system, including the interaction and communication between different networks of metabolism, transcription regulation and signal transduction. How to utilize the -omics data to generate a systematic and global knowledge about life are crucial to overcome the challenges currently we are facing.

On the other hand, how to effectively integrate the current research findings on synthetic biology is a key step to promote the development of synthetic biology. Moreover, during the first decade of synthetic biology, most researches focused on single module design. How to combine the different single modules to perform more complex functions is another key point to overcome. For example, the combined modules are supposed to produce green energy while consuming pollutants, or to detect and kill cancer cells [14]. Meanwhile, study on minimal genomes also plays an important role in future development of synthetic biology. Minimal genome study can not only provide proper chassis for newly designed modules, but also provide clues for exploring life forms.

\subsection{Social and ethical issues}

Science is always like a double-edged sword. While mentioning synthetic life or synthetic biology, some people do feel worried. Especially in 2008, when Becker et al. 
synthesized the SARS virus, it caused the panic in the public. People cannot help challenging that if such technology was managed by terrorists, what will happen? This year, when Venter's team in JCVI announced that they created the first synthetic cell, the panic was raised again in the public. On May 27, 2010, J. Craig Venter made a testimony before the U.S. House of Representatives Committee on Energy and Commerce. Venter said that all their studies adhered to the state regulations. They have made extensive discussions on the bio-security and bio-safety implications of synthetic genomics and they have also explored the risks and benefits of the emerging technology, as well as possible safeguards to prevent abuse.

Actually, from the technical point of view, scientists have predicted the potential risks and also have had preventive measures. For example, the suicide gene can be used to kill the engineered cell once it developed in a wrong way; some designed cell can only survive under certain conditions, and some engineered cell only has limited age. On the other hand, from the social point of view, regulations on bio-security and bio-safety should be proposed. First, government should strengthen the management. Second, scientists should fulfill their responsibility to prevent the abuse of such techniques. Third, the public should be educated to have a objective understanding of the new technology to avoid unnecessary panic (http://world.people.com.cn/GB/ 57507/11806145.html). An assessment from related ethical committee in U.S. said that currently synthetic biology will not produce huge unexpected destructive influence, but long-term supervision should be paid and appropriate measures should be formulated and implemented to avoid the risk.

\section{Summary and prospect}

It can be foreseen that, in the future, by using synthetic biology techniques, people will have artificial leafs to consume carbon dioxide while producing green energy. As mentioned above, synthetic biology will have the big potential to address a wide range of application including medicine, environment, energy, agriculture and so on.

Synthetic biology is still in its infancy in China. How to make full use of the current achievements and to establish our own research platform for synthetic biology is one of the important issues we are facing. Meanwhile synthetic biology research in China should cater for the national needs aiming to benefit the whole society. Since synthetic biology is a cross-disciplinary field, researchers from different areas should strengthen communication and cooperation to promote the development of synthetic biology in China. Scientists in China have the ability to make great achievements in this field and we look forward that synthetic biology will bring great impact on our future economical and social development.
Programme (Project PROBACTYS; 29104) and the National Natural Science Foundation of China (30700441).

1 Gibson D G, Glass J I, Lartigue C, et al. Creation of a bacterial cell controlled by a chemically synthesized genome. Science, 2010, 329: 52-56

2 The Royal Academy of Engineering. Synthetic Biology: Scope, Applications and Implications. London: The Royal Academy of Engineering, 2009

3 Benner S A, Sismour A M. Synthetic biology. Nat Rev Genet, 2005, 438: 533-543

4 Heinemann M, Panke S. Synthetic biology-putting engineering into biology. Bioinformatics, 2006, 22: 2790-2799

5 Leonard E, Nielsen D, Solomon K, et al. Engineering microbes with synthetic biology frameworks. Trends Biotechnol, 2008, 26: 674-681

6 Kitney R I. Synthetic biology-Engineering biologically-based devices and systems. In: Jarm T, Kramar P, Zupanic A, eds. 11th Mediterranean Conference on Medical and Biological Engineering and Computing (MEDICON 2007), Jun 26-30, 2007, Ljubljana, Slovenia. Berlin: Springer-Verlag Berlin, 2007. 1138-1139

7 Khalil A S, Collins J J. Synthetic biology: Applications come of age. Nat Rev Genet, 2010, 11: 367-379

8 Koonin E V. How many genes can make a cell: The minimal-geneset concept. Annu Rev Genomics Hum Genet, 2000, 1: 99-116

9 Szathmáry E. Life: In search of the simplest cell. Nature, 2005, 433: $469-470$

10 Zhang L, Chang S, Wang J. How to make a minimal genome for synthetic minimal cell. Protein Cell, 2010, 1: 427-434

11 Gardner T S, Cantor C R, Collins J J. Construction of a genetic toggle switch in Escherichia coli. Nature, 2000, 403: 339-342

12 Elowitz M B, Leibler S. A synthetic oscillatory network of transcriptional regulators. Nature, 2000, 403: 335-338

13 Editorial. Ten years of synergy. Nature, 2010, 463: 269-270

14 Purnick P E M, Weiss R. The second wave of synthetic biology: From modules to systems. Nat Rev Mol Cell Biol, 2009, 10: 410-422

15 Yokobayashi Y, Weiss R, Arnold F H. Directed evolution of a genetic circuit. Proc Natl Acad Sci USA, 2002, 99: 16587-16591

16 Elowitz M B, Levine A J, Siggia E D, et al. Stochastic gene expression in a single cell. Science, 2002, 297: 1183-1186

17 Martin V J, Pitera D J, Withers S T, et al. Engineering a mevalonate pathway in Escherichia coli for production of terpenoids. Nat Biotechnol, 2003, 21: 796-802

18 You L, Cox R S, Weiss R, et al. Programmed population control by cell-cell communication and regulated killing. Nature, 2004, 428: $868-871$

19 Kramer B P, Viretta A U, El Baba M D, et al. An engineered epigenetic transgene switch in mammalian cells. Nat Biotechnol, 2004, 22: 867-870

20 Basu S, Gerchman Y, Collins C H, et al. A synthetic multicellular system for programmed pattern formation. Nature, 2005, 434: 11301134

21 Chen M T, Weiss R. Artificial cell-cell communication in yeast Saccharomyces cerevisiae using signaling elements from Arabidopsis thaliana. Nat Biotechnol, 2005, 23: 1551-1555

22 Ro D K, Paradise E M, Ouellet M, et al. Production of the antimalarial drug precursor artemisinic acid in engineered yeast. Nature, 2006, 440: 940-943

23 Deans T L, Cantor C R, Collins J J. A tunable genetic switch based on RNAi and repressor proteins for regulating gene expression in mammalian cells. Cell, 2007, 130: 363-372

24 Rinaudo K, Bleris L, Maddamsetti R, et al. A universal RNAi-based logic evaluator that operates in mammalian cells. Nat Biotechnol, 2007, 25: 795-801

25 Win M N, Smolke C D. A modular and extensible RNA-based gene-regulatory platform for engineering cellular function. Proc Natl Acad Sci USA, 2007, 104: 14283-14288

26 Lou C, Liu X, Ni M, et al. Synthesizing a novel genetic sequential logic circuit: a push-on push-off switch. Mol Syst Biol, 2010, 6: 350 
27 Bronson J E, Mazur W W, Cornish V W. Transcription factor logic using chemical complementation. Mol Biosyst, 2008, 4: 56-58

28 Zhang Y H P, Evans B R, Mielenz J R, et al. High-yield hydrogen production from starch and water by a synthetic enzymatic pathway. PLoS ONE, 2007, 2: e456

29 Steen E J, Kang Y S, Bokinsky G, et al. Microbial production of fatty-acid-derived fuels and chemicals from plant biomass. Nature, 2010, 463: 559-562

30 Fraser C M, Gocayne J D, White O, et al. The minimal gene complement of Mycoplasma genitalium. Science, 1995, 270: 397-403

31 Mushegian A R, Koonin E V. A minimal gene set for cellular life derived by comparison of complete bacterial genomes. Proc Natl Acad Sci USA, 1996, 93: 10268-10273

32 Koonin E V. Comparative genomics, minimal gene-sets and the last universal common ancestor. Nat Rev, 2003, 1: 127-136

33 Akerley B J, Rubin E J, Novick V L, et al. A genome-scale analysis for identification of genes required for growth or survival of Haemophilus influenzae. Proc Natl Acad Sci USA, 2002, 99: 966-971

34 Glass J I, Assad-Garcia N, Alperovich N, et al. Essential genes of a minimal bacterium. Proc Natl Acad Sci USA, 2006, 103: 425-430

35 Jacobs M A, Alwood A, Thaipisuttikul I, et al. Comprehensive transposon mutant library of Pseudomonas aeruginosa. Proc Natl Acad Sci USA, 2003, 100: 14339-14344

36 Kobayashi K, Ehrlich S D, Albertini A, et al. Essential Bacillus subtilis genes. Proc Natl Acad Sci USA, 2003, 100: 4678-4683

37 Liberati N T, Urbach J M, Miyata S, et al. An ordered, nonredundant library of Pseudomonas aeruginosa strain PA14 transposon insertion mutants. Proc Natl Acad Sci USA, 2006, 103: 2833-2838

38 Ji Y, Zhang B, Van S F, et al. Identification of critical staphylococcal genes using conditional phenotypes generated by antisense RNA. Science, 2001, 293: 2266-2269

39 Zhang Y, Thiele I, Weekes D, et al. Three-dimensional structural view of the central metabolic network of Thermotoga maritima. Science, 2009, 325: 1544-1549

40 Fehér T, Papp B, Pál C, et al. Systematic genome reductions: Theoretical and experimental approaches. Chem Rev, 2007, 107: 3498-3513

41 Baba T, Ara T, Hasegawa M, et al. Construction of Escherichia coli K-12 in-frame, single-gene knockout mutants: The Keio collection. Mol Syst Biol, 2006, 2, doi: 10.1038/msb4100050

42 Sung B H, Lee J H, Kim S C. Escherichia coli genome engineering and minimization for the construction of a bioengine. In: Lee S Y, ed. Systems Biology and Biotechnology of Escherichia coli. Daejeon: Springer, 2009. 19-40

43 Goryshin I Y, Naumann T A, Apodaca J, et al. Chromosomal deletion formation system based on Tn5 double transposition: Use for making minimal genomes and essential gene analysis. Genome Res, 2003, 13: 644-653

44 Yu B J, Sung B H, Koob M D, et al. Minimization of the Escherichia coli genome using a Tn5-targeted Cre/loxP excision system. Nat Biotechnol, 2002, 20: 1018-1023

45 Kolisnychenko V, Plunkett G 3rd, Herring C D, et al. Engineering a reduced Escherichia coli genome. Genome Res, 2002, 12: 640-647

46 Posfai G, Plunkett G 3rd, Feher T, et al. Emergent properties of reduced-genome Escherichia coli. Science, 2006, 312: 1044-1046

47 Mizoguchi H, Mori H, Fujio T. Escherichia coli minimum genome factory. Biotechnol Appl Biochem, 2007, 46: 157-167

48 Hashimoto M, Ichimura T, Mizoguchi $\mathrm{H}$, et al. Cell size and nucleoid organization of engineered Escherichia coli cells with a reduced genome. Mol Microbiol, 2005, 55: 137-149

49 Westers H, Dorenbos R, van Dijl J M, et al. Genome engineering reveals large dispensable regions in Bacillus subtilis. Mol Biol Evol, 2003, 20: 2076-2090

50 Ara K, Ozaki K, Nakamura K, et al. Bacillus minimum genome factory: Effective utilization of microbial genome information.
Biotechnol Appl Biochem, 2007, 46: 169-178

51 Morimoto T, Kadoya R, Endo K, et al. Enhanced recombinant protein productivity by genome reduction in Bacillus subtilis. DNA Res, 2008, 15: 73-81

52 Suzuki N, Nonaka H, Tsuge Y, et al. Multiple large segment deletion method for Corynebacterium glutamicum. Appl Microbiol Biotechnol, 2005, 69: 151-161

53 Giga-Hama Y, Tohda H, Takegawa K, et al. Schizosaccharomyces pombe minimum genome factory. Biotechnol Appl Biochem, 2007, 46: $147-155$

54 Murakami K, Tao E, Ito Y, et al. Large scale deletions in the Saccharomyces cerevisiae genome create strains with altered regulation of carbon metabolism. Appl Microbiol Biotechnol, 2007, 75: 589-597

55 Agarwal K L, Büchi H, Caruther M H, et al. Total synthesis of gene for an alanine transfer ribonucleic acid from yeast. Nature, 1970, 227: 27-34

56 Cello J, Paul A V, Wimmer E. Chemical synthesis of poliovirus cDNA: Generation of infections virus in the absence of natural template. Science, 2002, 297: 1016-1018

57 Smith $\mathrm{H}$ O, Hutchison C A, Pfannkoch C, et al. Generating a synthetic genome by whole genome assembly: $\Phi$ X174 bacteriophage from synthetic oligonucleotides. Proc Natl Acad Sci USA, 2003, 100: 15440-15445

58 Kobasa D, Takada A, Shinya K, et al. Enhanced virulence of influenza A viruses with the haemagglutinin of the 1918 pandemic virus. Nature, 2004, 431: 703-707

59 Becker M M, Graham R L, Donaldson E F, et al. Synthetic recombinant bat SARS-like coronavirus is infectious in cultured cells and in mice. Proc Natl Acad Sci USA, 2008, 105: 19944-19949

60 Foley $\mathrm{P}$ L, Shuler M L. Considerations for the design and construction of a synthetic platform cell for biotechnological applications. Biotechnol Bioeng, 2010, 105: 26-36

61 Pennisi E. Synthetic genome brings new life to bacterium. Science, 2010, 328: 958-959

62 Hutchison C A, Peterson S N, Gill S R, et al. Global transposon mutagenesis and a minimal mycoplasma genome. Science, 1999, 286: 2165-2169

63 Lartigue C, Glass J I, Alperovich N, et al. Genome transplantation in bacteria: Changing one species to another. Science, 2007, 317: 632-638

64 Gibson D G, Benders G A, Andrews-Pfannkoch C, et al. Complete chemical synthesis, assembly, and cloning of a Mycoplasma genitalium genome. Science, 2008, 319: 1215-1220

65 Gibson D G, Benders G A, Axelrod K C, et al. One-step assembly in yeast of 25 overlapping DNA fragments to form a complete synthetic Mycoplasma genitalium genome. Proc Natl Acad Sci USA, 2008, 105: 20404-20409

66 Lartigue C, Vashee S, Algire M A, et al. Creating bacterial strains from genomes that have been cloned and engineered in yeast. Science, 2009, 325: 1693-1696

67 Zhang R, Lin Y. DEG 5.0, a database of essential genes in both prokaryotes and eukaryotes. Nucleic Acids Res, 2009, 37: D455-D458

68 Zhang R, Ou H, Zhang C. DEG: A database of essential genes. Nucleic Acids Res, 2004, 32: D271-D272

$69 \mathrm{Hu} \mathrm{B}, \mathrm{Du}$ J, Zou R-Y, et al. An environment-sensitive synthetic microbial ecosystem. PLoS ONE, 2010, 5: e10619

70 Luo J, Wang J, Ma T M, et al. Reverse engineering of bacterial chemotaxis pathway via frequency domain analysis. PLoS ONE, 2010, 5: e9182

71 Zhan J, Ding B, Ma R, et al. Develop reusable and combinable designs for transcriptional logic gates. Mol Syst Biol, 2010, 6: 388

72 Kwok R. Five hard truths for synthetic biology. Nature, 2010, 463: 288-290

73 Alterovitz G, Muso T, Ramoni M F. The challenges of informatics in synthetic biology: From biomolecular networks to artificial organisms. Brief Bioinform, 2010, 11: 80-95

Open Access This article is distributed under the terms of the Creative Commons Attribution License which permits any use, distribution, and reproduction in any medium, provided the original author(s) and source are credited. 